\title{
Consolidation of a professional approach experience on motivating Computer Engineering Students to the application of legal issues
}

\section{Lozano, Mayte $^{\mathrm{a}}$ and Trillo-Lado, Raquel ${ }^{\mathrm{b}}$}

${ }^{\mathrm{a} C}$ Centro Universitario de la Defensa, Univ. de Zaragoza, Spain, ${ }^{\mathrm{b}}$ Depto. de Informática e Ingeniería de Sistemas, Univ. de Zaragoza, Spain

\section{Abstract}

In previous courses, professors of the degree of Computer Science and Software Engineering of the University of Zaragoza realised that students did not like studying materias related to Legislation and Information Systems. However, these topics are key when Computers Science and Software Engineers have to analyse, design, implement, and mantain Information Systems in different environments such as an enterprise, a public entity, etc. because the rights of the users/clients of these systems must be guaranteed. So, a more appeling way to teach those topics to motivate the students to take them into account was designed.

This paper describes the methodology and the main activities designed in the $2014 / 2015$ and 2015/2016 courses in order to get the attention of the students on topics related to the current Spanish legislation and Information Systems. Moreover, some indicators about the performance of the students and their opinions about this new methodology are also described and analysed.

Keywords: project based learning; problem based learning; professional approach; active learning; legislation; information systems. 


\section{Introduction}

Thanks to the development of Information and Communication Technology (ICT), during the last decades, there has been a huge increase in the amount of digitized data available to be processed. This has led to new business models and applications in many areas and sectors. So, the development of ICT has generated the need to create and adapt legislation in order to guarantee people rights in the context of Information Society. In the Spanish scope, it is important to consider the Ley Orgánica 15/1999, de 13 de diciembre, de Protección de Datos de Carácter Personal (LOPD; Personal Data Protection) and the Real Decreto 1720/2007, de 21 de diciembre, de aprobación del Reglamento de desarrollo de la LOPD (RLOPD; regulations implementing the LOPD). Some institutions, as the Agencia Española de Protección de Datos (AEPD; Spanish Agency for Data Protection) have already taken care of publishing this framework and try to ensure its compliance. Nevertheless, a high percentage of Small and Medium Enterprises (SMEs) are not aware of being subjected to this law framework, according to data provided by the Instituto Nacional de Tecnologías de la Comunicación (INTECO; National Institute for Communication Technologies), (Pérez San-José, Gutiérrez Borge, et al, 2012).

The learning objective here is to consolidate and improve the experience introduced last course (2014-2015), in order to engage Computer Engineering students of the need to respect regulations. In order to obtain these goals, we propose problem and project based learning by applying practical tasks of an Information System course on a research project.

This paper is organized as follows. First of all, a brief description of the technological project is presented. Then, the methodology proposed for the learning process is depicted. After that, technologies used by the students are described. Later on, results of this experience are discussed. Finally, some conclusions are drawn and future work is introduced, as well as sustainability and maintainability.

\section{Bioinformatics Research Project}

As it was previously mentioned, thanks to the development of ICT, there has been a huge increase in the amount of digitized data available to be processed. Thanks to that, some new business models and some new applications in many areas have been introduced. For example, in the health scope has emerged the bioinformatic area and there has been an increase in SMEs, and emerging research groups that develop management and processing systems of biomedical signals (signals originated by the human body, used in diagnosis or medical research) with different goals.

As we were involved in the development of one of those biomedical projects, we decided to take the advantage of using the project in order to motivate students to understand and to 
apply legal issues when developing any information system from its firsts stages. The research project used in the experience has the reference CUD2013-11 (Peláez Coca, 2014). Its title, translated to English, is: Identifying Situations where Military personnel Performance is Decreased, based on the relationship of Heart Rate Variability with Stress and Sleep Deprivation. The ultimate goal of this project is to develop an automatic identifier of the operating performance of security and defence personnel from biomedical signals for carrying out activities with great physical and/or cognitive requirements. To this end, different multimodal biosignals are registered in several experimental subjects, while they face a highly stressful task with great cognitive requirements. A big amount of biological and personal data is managed at Centro Universitario de la Defensa de Zaragoza, where the project is developed. Refer to bibliography in case more information about the project is needed (Aiger et al., 2014).

Since data managed in the introduced projet is not only important for the project but also sensitive, as they are personal and also biomedical data, the relevance of its safety is really high. So, a series of guides defining behaviour protocols, were developed during the first part of the project. They introduce the convenience of the application of safety politics from the very beginning of every information system project (Lozano \& Trillo-Lado, 2014). That is why we thought that this was the best environment to learn the importance of applying the normative and legal framework, and to do it from the first draft; despite the fact students enrolled Information Systems course had already taken lessons about legal issues, they did not apply those concepts, techniques or tools to design and implement their own systems.

As in the first experience the research project was used with good results, we decided to use it again as the project is still active. The idea for future experiences is to change the research project used. In spite of that, this course we preferred to focus our efforts on improving methodology.

\section{Methodology used in the learning process}

Target audience of this experience of professional approach are the students of the Information Systems course in the Computer Engineering Degree taught at the Escuela de Ingeniería y Arquitectura, Universidad de Zaragoza. In general, during the development of practices and problems of the course, students often worked with simple examples that do not motivate them. Besides, aspects of legislation in the field of ICT in a Computer Engineering degree do not usually appeal to students. Therefore, last academic year (20142015), we proposed to students working and developing their practice in a research project of the Centro Universitario de la Defensa (Peláez Coca, 2014). Briefly, the main innovation introduced by this work was the use of a real development and technological innovation 
project, in order to motivate students to study existing legislation and norms on issues related to ICT and Information Systems.

Apart from the importance of the fulfilment of the law, one of the main ideas to be conveyed to students is that it is necessary to consider the security aspects of the storage, processing and transmission of data and information from the beginning of the project; and not only when implementing and parameterizing specific software. So, we try to introduce these ideas to students using some activities based on previous expertise. Thus, we designed a set of practices and problems to be solved in the classroom which were related to tasks to be performed on the CUD project following the methodologies and indications of Problem Based Learning and Project Based Learning (Blumenfeld, 1991; Luarattana et al., 2010; and Wood, 2003). Moreover, we estimated the workload of the practices assessment proposed to students; and designed the development of the practice and problem sessions.

\section{Technology used in the learning process}

In relation to the technologies used in this new experience, the same technologies as last course were proposed to students. So, several web technologies were explained and proposed to develop the Web Applications: HTML, CSS, Apache-Tomcat, relational and object-relational databases (Oracle, PostgreSQL, Cache, MySQL), middleware mapping object-relational (Hibernate with JPA), Java, JDBC and J2EE. Nevertheless, students are allowed to select other technologies and frameworks in order to develop their information systems. At the end of the term, we will see if those technologies were different from the ones chosen last year and the rate of students that used the proposed ones.

\section{Results and Discussion}

In general, during the development of practices and problems students often work with simple examples that do not motivate them. Besides, topics related to legislation and ICT in a Computer Science and Engineering degree do not usually appeal to students. However, through this experience students increase their knowledge of Information Systems and legal issues, especially the expertise and know how, in the context of an actual professional approach. In addition, students learn it in a more entertaining way, thanks to their increased motivation, because the obtained results are applied on a real project that is already ongoing.

In order to get the final results of the experience this course (2015-2016), some activities remain to be accomplished; for example the survey, the interview and the final evaluation for the students have not been completed yet. In more detail, to evaluate the new 
methodology and activities designed to foster the process of learning basics of legislation and norms in the field of ICT, several surveys will be completed by the students after the end of the course. Moreover, at least four students will be interviewed (two from the current academic course and two from the previous one) in order to compare the assimilation of legal concepts related to Information Systems.

\section{Conclusions}

In order to get the final results, students at the end of the course should complete a survey and a minimum of four students should be interviewed (two from the current academic year and one from the previous one, in order to compare the assimilation of concepts). Before having these data, only the perception of the teachers can be analysed. Professors consider that concepts are better understood using the ideas here applied, thus we think that the main point is that students are motivated due to the relation of the activities they do with a real project. In fact, we got the perception that anything real motivate them, especially if it is usefull for someone, as it is the case here with the research project.

\section{Future Work}

If the results are so good as expected, we plan to repeat the experience, improving some aspects and changing the research project used. The objective in changing the research project used to motivate students is to use an active project, as the one we are using this course is about to finish (at the end of 2016). Next course (2016-2017), we will probably use the project described in (Lozano, Trillo_Lado, 2015).

\section{Sustainability and Transferability}

In relation to sustainability, this experience can be repeated in subsequent years in the same subject, using as a basis new projects that would be useful for the implementation of the tasks that are part of the course.

Regarding to transferability, the idea of approaching to a professional development project in an academic degree course could be exported to other related subjects. In fact, we are already doing it, in an innovation project where we share our experience with teachers who are responsible of other materias in the same area such as Databases, Web Engineering, etc. (PIIDUZ_15_296). 
Consolidation of a professional approach experience on motivating Computer Engineering Students to the application of legal issues

\section{Acknowledgements}

This work has been partially supported by Red EULES, from Universidad de Zaragoza, project PIIDUZ_15_296 from Universidad de Zaragoza, project CUD2013-11 from Centro Universitario de la Defensa de Zaragoza, project TEC2014-54143-P from Ministerio de Economía y Competitividad and COST action Keystone IC1302.

\section{References}

Aiger, Montserrat, García-Laencina, P., Lozano, M., Peláez Coca, M.D., Roca-Dorda, J., Roca-González, J., Rodríquez-Bermudez, G., Sancho, J.J., Serna, J., \& Trillo_Lado, R. (2014). Indicadores somáticos en el estudio del rendimiento en el personal de Seguridad y Defensa. In Dena Arto, A., Sánchez Rúa, M.T., \& Martínez Torres, J. (eds.) Actas: II Congreso Nacional de $i+d$ en Defensa y Seguridad, DESEi+d 2014 (pp. 527-535). Ed. Centro Universitario de la Defensa Zaragoza.

Blumenfeld, P. C., Soloway, E., Marx, R. W., Krajcik, J. S., Guzdial, M., \& Palincsar, A. (1991). Motivating project-based learning: Sustaining the doing, supporting the learning. Educational psychologist, 26(3-4), 369-398.

Lozano, M., \& Trillo_Lado, R. (2014). Experiencia en el desarrollo de un sistema de información para la gestión de señales biomédicas en PYMES y grupos de investigación emergentes. In Dena Arto, A., Sánchez Rúa, M.T., \& Martínez Torres, J. (Eds.) Actas: II Congreso Nacional de $i+d$ en Defensa y Seguridad DESEi+d 2014 (pp. 637-644). Ed. Centro Universitario de la Defensa Zaragoza.

Lozano, M., \& Trillo_Lado, R. (2015). Monitorización de la temperatura en camiones frigoríficos. In Actas: III Congreso Nacional de $i+d$ en Defensa y Seguridad DESE $i+d$ 2015. Vigo: Centro Universitario de la Defensa Vigo.

Lozano, M. (Coord.; 2014). Acercamiento a la realidad profesional: desde un proyecto informático a la asignatura Sistemas de Información, PIIDUZ_14_529. 2014-2015.

Trillo_Lado, R. (Coord.; 2015). Involucrando a los estudiantes de Sistemas de Información y Bases de Datos en la resolución de retos planteados por empresas y grupos de investigación, PIIDUZ_15_296.2015-2016.

Luanrattana, R., Win, K. T., \& Fulcher, J. (2010). Data security and information privacy for PDA accessible clinical-log for medical education in problem-based learning (PBL) approach. In Advanced Information Networking and Applications Workshops (WAINA), IEEE 24th International Conference on Advanced Information Networking and Applications Workshops (pp. 979-984). ISBN 978-0-7695-4019-1/10. DOI 10.1109/WAINA.2010.42

Luanrattana, R., Win, K.T., Fulcher, J., \& Iverson, D. (2010), Adoption of Mobile Technology in a Problem-Based Learning Approach in Medical Education, International Journal of Mobile Learning and Organisation, Vol. 4 (3), pp. 294-316.

Peláez Coca, M.D. (I.P.; 2014). Identificación de situaciones de disminución del rendimiento del militar, basado en la relación de la variabilidad del ritmo cardiaco con el estrés y la privación de sueño, CUD2013-11. 1/1/2014-31/12/2016. 
Pérez San-José, P., Gutiérrez Borge, C., Álvarez Alonso, E., García Pérez, L., \& de la Fuente Rodríguez, S. (2012). Estudio sobre seguridad de la información y continuidad de negocio en las PYMES españolas. Informe Instituto Nacional de Tecnologías de la Información.

Wood, D. F. (2003). Problem based learning. Bmj, 326(7384), 328-330. 